\title{
ANTICLERICALISMO Y PRIMERA VIOLENCIA EN LA DIÓCESIS DE NUEVA PAMPLONA, COLOMBIA (1930-1934): CLERO, POLÍTICOS, JUECES Y POLICÍAS
}

\author{
POR \\ María Del Rosario VázQuez Piñeros \\ Departamento de Historia y Estudios Socioculturales \\ Facultad de Filosofía y Ciencias Humanas, Universidad de La Sabana
}

\begin{abstract}
RESUMEN
El presente artículo aborda las estrategias anticlericales de las autoridades liberales en la Diócesis de Nueva Pamplona, Colombia, durante el gobierno de Enrique Olaya (1930-34). Dichas estrategias tuvieron como principal objetivo minar la imagen de los párrocos y, en consecuencia, reducir su poder de convocatoria electoral a favor del conservatismo. Con el fin de ampliar las posibles explicaciones de este fenómeno, se contrastaron diferentes tipos de fuentes - hemerográficas y documentales, civiles y eclesiásticas - de diversa proveniencia política.
\end{abstract}

Palabras ClaVe: Iglesia Católica, Concentración Nacional, Violencia Bipartidista, Anticlericalismo, Colombia.

\section{ANTICLERICALISM AND FIRST VIOLENCE IN THE DIOCESE OF NUEVA PAMPLONA, COLOMBIA (1930-1934): CLERGY, POLITICIANS, JUDGES AND POLICE ${ }^{1}$}

\begin{abstract}
This paper deals with the anti-clerical strategies put forth by Liberal authorities in the Diocese of Nueva Pamplona, Colombia, during the administration of
\end{abstract}

\footnotetext{
${ }^{1}$ El presente artículo es resultado del proyecto de investigación de la Facultad de Filosofía y Ciencias Humanas de la Universidad de La Sabana Iglesia y política en la Concentración Nacional (1929-1934). El conflicto entre tradición y modernidad en el marco del proceso de secularización en Colombia (HUM31-2010) y de la tesis doctoral de la autora. Cfr. Vázquez Piñeros, M. 2012. Iglesia y Estado en Colombia durante el gobierno de la Concentración Nacional: clero, partidos y violencia, 1929-1934 (Tesis de grado).
} 
Enrique Olaya (1930-34). These strategies had the intention of undermining the public image of parish priests in order to reduce their power of drawing people to the polls in favor of the Conservative Party. To attain a wider understanding of this phenomenon and its causes, varied sources - press, public and ecclesiastical documents - of diverse political affiliation were compared.

KEY WORDS: Catholic Church, National Concentration, Bipartisan Violence, Anticlericalism, Colombia.

Recibido/Received: $\quad$ 04-10-2010

Aceptado/Accepted: $\quad$ 01-10-2013

A mediados del siglo XIX se conformaron los dos partidos tradicionales colombianos, el liberal (1848) y el conservador (1849). Desde entonces el enfrentamiento armado entre ellos hizo parte consustancial de la historia política del país hasta que en 1958 se firmaron los acuerdos del Frente Nacional (1958-1974). ${ }^{2}$ A lo largo de estas luchas la bandera religiosa, en el caso de los conservadores, y la anticlerical, para los liberales, ocupó un lugar de primer orden en la definición de las identidades partidistas y en los respectivos proyectos de construcción nacional. En ese contexto, la situación de la Iglesia dependió en gran medida de los resultados electorales. Por ejemplo, los gobiernos liberales sucedidos entre 1849 y 1885 (con excepción de las dos presidencias conservadoras de Manuel María Mallarino y de Mariano Ospina Rodríguez, entre 1855-57 y 1857-1861, respectivamente), instauraron reformas y llevaron a cabo medidas contrarias a la Iglesia, entre ellas, por ejemplo, el destierro de obispos y la desamortización de los bienes eclesiásticos. Una vez los conservadores llegaron al poder, la Iglesia recuperó los derechos que tradicionalmente el Estado le había reconocido y firmó un Concordato (1887) con el gobierno

Vitoria-Gasteiz: Universidad del País Vasco. Este trabajo contó con la generosa colaboración del programa de ayudas para la estancia en la UPV/EHU, otorgadas al alumnado latinoamericano. Agradezco al Dr. Juan Bosco Amores Carredano, director de tesis, su invaluable contribución en esta investigación.

${ }^{2}$ A lo largo del siglo xix hubo siete guerras civiles, la última de ellas la de los Mil Días (18991902), y por lo menos cuarenta levantamientos regionales. Durante el xx, el conflicto bipartidista dio paso a la Violencia (1930-1958), caracterizada por confrontaciones armadas en las zonas rurales sin una guerra civil formalmente declarada. El Frente Nacional puso fin a dicho enfrentamiento al garantizar la repartición paritaria del poder entre liberales y conservadores a lo largo de dieciséis años. Entre 1958 y 1974, los dos sectores alternaron en la presidencia de la república. Sin embargo, esta dinámica electoral resultó excluyente al dejar por fuera a otras fuerzas políticas alternativas que no encontraron la manera de canalizar su participación por medios democráticos. Este proceso explica, en parte, el origen de las guerrillas comunistas durante el Frente Nacional, paradójicamente creado para resolver un siglo y medio de luchas liberal-conservadoras.

Hispania Sacra, LXVI

133, enero-junio 2014, 263-285, ISSN: 0018-215X, doi: 10.3989/hs.2013.053 
colombiano. A partir de entonces el Estado le garantizaría protección y la educación quedaba bajo su tutela. ${ }^{3}$

Hacia 1930, el ascenso a la presidencia de Enrique Olaya Herrera (1930-34) dio paso a la República Liberal (1930-1946) y puso fin a cuarenta y cinco años de hegemonía conservadora (1885-1930). Esto desató un ambiente de tensión entre los partidos, a pesar de los acuerdos de la Concentración Nacional que aseguraban un porcentaje de participación al conservatismo. ${ }^{4} \mathrm{El}$ nuevo gobierno, de acuerdo con la Constitución centralista de 1886, llevó a cabo el correspondiente reemplazo de gobernadores y alcaldes. Aunque en las capitales de los departamentos se hizo un traspaso pacífico del poder, en las zonas rurales los cambios no siempre fueron tan bien recibidos por el partido saliente. Los conservadores, conscientes de que aún constituían la mayoría del electorado, no se resignaban al fracaso. A su vez, las nuevas autoridades regionales del liberalismo, apoyadas por los cuerpos de policía, llevaron a cabo retaliaciones, producto del resentimiento por los excesos cometidos por el partido conservador durante su largo predominio en el poder; así mismo, comenzaron a tomar decisiones que condujeran a su partido al triunfo electoral en los siguientes comicios. Este proyecto supuso, en primer lugar, garantizar la victoria en las urnas en aquellas localidades predominantemente liberales, pero en donde los conservadores habían defraudado sistemáticamente a su favor los resultados de las votaciones; $\mathrm{y}$, por otra parte, la disminución del electorado conservador, a cualquier costo - lo que significó el ejercicio de prácticas violentas que incluyeron el asesinato y el desplazamiento-, objetivos que a la larga consiguieron puesto que de aquí en adelante y tras dieciséis años de gobierno, el liberalismo pasó a convertirse en el partido mayoritario de Colombia. ${ }^{5}$

\footnotetext{
${ }^{3}$ Asociación de Hombres Libres de Colombia (ed.). 1962. El Concordato celebrado entre el Papa León XIII y el Dr. Rafael Núñez, presidente de Colombia: 36 Bogotá: AHLC.

${ }^{4}$ Durante la campaña electoral de 1929, Enrique Olaya Herrera aceptó la candidatura liberal a la presidencia de la república. Su programa tomó el nombre de Concentración Nacional, puesto que ofrecía a los conservadores que lo apoyaran una cuota de participación en su gobierno. Quienes se adhirieron a esta propuesta, como el expresidente Carlos E. Restrepo, lo hicieron con la condición de que se garantizara el respeto a los acuerdos del Concordato. Cfr. AA. Dr. Enrique Olaya Herrera, salvador de la República, 1930: 24; Vázquez Piñeros, M. 2012. «Clero y violencia durante la Concentración Nacional»: 197-252.

${ }^{5}$ Sobre los mecanismos empleados por el liberalismo para hacerse con el control electoral y agrario en el departamento del Valle del Cauca, al suroccidente del país, Cfr. Betancourt, D. García, M. 1990. Matones y cuadrilleros: 35-55 Bogotá: Tercer Mundo; Quintero Restrepo, L. D. 2008. «Los "Pájaros" del Valle del Cauca». Revista Estudios de Derecho 145: 245-257. Otro aspecto importante que ayudó a consolidar las mayorías liberales en los años treinta, fue su discurso a favor de las reformas sociales y, en concreto, algunos proyectos como los del presidente Alfonso López, propuestos en la reforma constitucional de 1936, bajo el nombre de Revolución en Marcha. Cfr. Tirado Mejía, Á. 1995. Aspectos políticos del primer gobierno de Alfonso López Pumarejo, (1934-1938): 68-113 Bogotá: Planeta. Los conservadores recuperaron el poder en 1946 con la presidencia de Mariano Ospina Pérez, a pesar de ser
} 
Lo anterior permite afirmar que la politización de las funciones del Estado y el ejercicio del poder con criterios marcadamente sectarios, obedeció a la estrategia de los dos partidos encaminada a la obtención del predominio electoral en las localidades a su cargo, según la distribución de alcaldías propiciada por el régimen de la Concentración, distribución que, como es claro, tendió a favorecer al partido del Presidente. ${ }^{6}$ Existe abundante documentación sobre las denuncias por abuso de autoridad en contra de los mandos civiles liberales y de la policía (municipal, departamental y, en menor medida, de la nacional). Estas autoridades cometieron graves atropellos contra la población conservadora. Es importante destacar que, en contrapartida, en algunos municipios donde se mantuvieron alcaldes o jueces conservadores, los liberales presentaron exactamente las mismas quejas. ${ }^{7}$ De esta manera, el poder del Estado a nivel local era usado por unos y otros para hostilizar a sus oponentes políticos. ${ }^{8}$ El choque de intereses y la violencia de los mecanismos empleados por ambas partes, terminaron por desatar una guerra regional no declarada y varias campañas de pacificación en los departamentos donde la situación fue más crítica: Boyacá, Santander y Norte de Santander, ubicados en la región centro y nororiental del país, y en menor medida en Tolima y Cundinamarca. ${ }^{9}$

minoría, debido a que el partido liberal dividió sus preferencias en las elecciones de ese año entre dos nombres: Gabriel Turbay, por el ala oficialista, y Jorge Eliécer Gaitán, candidato popular.

${ }^{6}$ Cfr. Acuña, O. Y. 2006. «Juego político y acción militar durante la República Liberal, una forma de violencia institucional», en Memorias del XIII Congreso Colombiano de Historia, (CD Rom). Bucaramanga: Universidad Industrial de Santander; y, de la misma autora: 2003. «Jornadas y fraude electoral en el departamento de Boyacá. 1930-1950», en I. C. Bermúdez (comp.), Poder regional y discurso étnico: 303-333. Cali: Universidad del Valle; Guerrero, J. 1991. Los años del olvido. Boyacá y los orígenes de la violencia: 122-125 Bogotá: Tercer Mundo Editores, Instituto de Relaciones Internacionales de la Universidad Nacional de Colombia. Según Isabel Caballero, la «política» es el término con que los campesinos de Boyacá explican la confrontación electoral entre liberales y conservadores, la cual también incluyó medios violentos, con el fin de triunfar en las urnas. Por otra parte, la «guerra» es el concepto usado por ellos mismos, para referirse a la aparición de las guerrillas comunistas y los paramilitares. Cabría suponer entonces, que en el imaginario de estos campesinos, este último conflicto se diferencia del primero porque su finalidad no es que el enfrentamiento se resuelva en las urnas, sino concretamente, por medio de las armas y a través del «control militar del territorio». Cfr. Caballero Samper, I. 2013. «La Política»: veintiún testimonios de La Violencia en las provincias Norte de Boyacá y García Rovira Santander: 15-19 y 27-28 Bogotá: Universidad de Los Andes.

7 Archivo General de la Nación (en adelante AGN), Archivo Anexo 2, Ministerio de Gobierno, Sección 4, Justicia, Orden Público-Informes, Caja 1, Carpeta 4, Buitrago y Ojeda a Mendoza Neira, 12 de julio de 1932, f. 107; Ibídem, Buitrago y Ojeda a los Ministros de Guerra y de Gobierno, 12 de julio de 1932, ff. 108 y 109.

${ }^{8}$ Sobre la parcialidad del Estado como causa estructural de la violencia bipartidista, Cfr. Oquist, P. 1978. Violencia, conflicto y política en Colombia: 244-245 y 255-269 Bogotá: Banco Popular.

${ }^{9}$ Cfr. Henderson, J. 2006. Los años de Laureano Gómez, 1889-1965: 267-275 Medellín: Universidad de Antioquia. Todavía no existe suficiente claridad acerca de la forma cómo se tejieron las redes de cobertura local, departamental y nacional que propiciaron la Violencia, puesto que tampoco es fácil acceder a la documentación que permita seguir este rastro. Evidentemente, porque estas pruebas

Hispania Sacra, LXVI

133, enero-junio 2014, 263-285, ISSN: 0018-215X, doi: 10.3989/hs.2013.053 
Fue así cómo a partir de las elecciones del treinta estallaron episodios violentos, especialmente en los departamentos mencionados, comparables cualitativamente a los que de manera más generalizada se presentarían en los años cuarenta y cincuenta (esta vez bajo los gobiernos conservadores de Mariano Ospina, Laureano Gómez y del general Gustavo Rojas Pinilla, entre 1946 y 1957), a lo largo y ancho del país. Si bien es cierto que muchas localidades se vieron afectadas por el conflicto bipartidista de esta primera etapa, es importante subrayar que la intensidad del mismo fue significativamente mayor en los departamentos del nororiente de Colombia, en donde las mayorías políticas de los dos bandos, en cada lugar, y autoridades inescrupulosas, expulsaron a sus adversarios y se apoderaron de sus propiedades, mientras cometían atroces asesinatos bajo la más absoluta impunidad.

Los bandos políticos se encontraban muy bien definidos. Del lado liberal estaban la policía, los guardias de rentas y grupos de civiles armados que acompañaban a los uniformados. Del conservador, sus respectivas policías cívicas, ${ }^{10}$ los bandoleros políticos, ${ }^{11}$ que contaban con el respaldo de los campesinos; y, por último, las autodefensas, ${ }^{12}$ cuyos miembros eran tildados por las autoridades también de bandoleros, a pesar de que presentaban una organización y un número mayor de integrantes. El ejército mostró una posición más ecuánime, profesional y menos sectaria, ${ }^{13}$ aunque, desde luego, encaminada prioritariamente a la represión de los conservadores alzados en armas.

incriminarían a jefes políticos dispuestos a hacer desaparecer los vestigios que pudieran vincularlos con estos hechos. Esto explica porqué las autoridades se vieron comprometidas con la desaparición de las investigaciones que las inculpaban a ellas y a sus copartidarios. Ver, por ejemplo: AGN, Archivo Anexo 2, Ministerio de Gobierno, Sección 4, Justicia, Orden Público-Informes, Caja 1, Carpeta 4, Navia Carvajal al Director de la Policía Nacional, 18 de septiembre de 1932, f. 149.

${ }^{10}$ Cfr. Sánchez, G. 1991. «Prólogo», en J. Guerrero. 1991: 20; Acuña, O. Y. 2003: 311-312.

${ }^{11}$ Una investigación pionera sobre el bandolerismo político correspondiente a la Violencia bajo los gobiernos conservadores (1946-58) y los primeros años del Frente Nacional (1958-74), en: Sánchez, G. Meertens, D. 2000. Bandoleros, gamonales y campesinos, el caso de la Violencia en Colombia: 25-28 y 42-61 Bogotá: Áncora editores. Acerca de los bandidos conservadores en la región de García Rovira (territorio en el que convergen los departamentos de Boyacá, Santander y Norte de Santander) durante los primeros años de la Hegemonía Liberal, ver: Guerrero, J. 1991: 159-160. Sin embargo, queda pendiente ampliar la investigación sobre el tema, con el fin de establecer las continuidades y rupturas de este fenómeno desde sus raíces antes, durante y después de la Hegemonía Liberal (1930-46).

12 AGN, Archivo Anexo 2, Ministerio de Gobierno, Sección 4, Justicia, Orden Público-Informes, Caja 1, Carpeta 3, Cadena Dacosta a Olaya Herrera, 2 de julio de 1932, f. 33; Ibídem, Alcalde de Capitanejo al Ministro de Gobierno, 2 de julio de 1932, ff. 34 y 35; Ibídem, Memorándum sobre la situación en los Santanderes (sin fecha), f. 81. Sobre las autodefensas conservadoras durante este periodo en la región de García Rovira, Cfr. J. Guerrero. 1991: 159-164.

${ }^{13}$ Cfr. Acuña, O. Y. 2006. «La policía partidista en Colombia, 1930-1953». Revista Educación y Ciencia 8: 111-116; AGN,Archivo Anexo 2, Ministerio de Gobierno, Sección 4, Justicia, CorrespondenciaTelegramas, Caja 3, Carpeta 3, Porras a Olaya Herrera, 15 de septiembre de 1932, f. 132. 
EL CLERO Y LA VIOLENCIA DURANTE LA CONCENTRACIÓN NACIONAL

Es difícil obtener respuestas definitivas sobre la controvertida participación del clero en política y la manera en que, durante la Primera Violencia, ${ }^{14}$ la Iglesia quedó articulada en el conflicto bipartidista. Primero, por la escasez de investigaciones específicas sobre el tema y, en segundo lugar, debido a la parcialidad de las fuentes. Desde que Germán Guzmán, en los años sesenta, se refiriera al conflicto entre las autoridades liberales de provincia y el clero en la diócesis de Nueva Pamplona ${ }^{15}$ lo cierto es que con contadas excepciones - entre las que habría que destacar la investigación sobre este mismo tema, en el norte de Boyacá, del historiador Helwar Figueroa,$-{ }^{16}$ la cuestión ha sido prácticamente olvidada hasta el día de hoy o, en el mejor de los casos, tangencialmente abordada por los especialistas. Dicho vacío ha repercutido en la formación de una idea a tal punto distorsionada, que se ha llegado a pensar que la cuestión religiosa no representó un factor de enfrentamiento entre los partidos durante el gobierno de Olaya Herrera. No obstante, a pesar de las intenciones conciliadoras del presidente, el ambiente para la Iglesia cambió en la capital de la república, $\mathrm{y}$, sobre todo, en las zonas de mayor tensión política. ${ }^{17}$

Recientemente, el historiador español Gustavo Arce Fustero ha efectuado interesantes comparaciones entre lo que él denomina «procesos de secularización tardía» en la España de la Segunda República y en la República Liberal colombiana. Esto lo ha llevado a indagar sobre los rasgos del conflicto

${ }^{14}$ En la publicación pionera Los años del olvido. Boyacá y los orígenes de la violencia, Javier Guerrero propuso el nombre «Primera Violencia» para referirse al conflicto bipartidista que se desató en la década del treinta, diferenciándolo así de la etapa consecutiva de violencia que vivió el país bajo los regímenes conservadores de los años cuarenta y cincuenta. Cfr. Guerrero, J. 1991: 53-55. Recientemente fue publicada la ya citada investigación de Isabel Caballero Samper, la cual, desde un enfoque interdisciplinar efectúa un análisis sobre el sentido y la explicación que los testigos sobrevivientes le dan a dicho conflicto, su relación con las más recientes confrontaciones con las guerrillas comunistas y el paramilitarismo, y la forma como desde la violencia se construyeron identidades sociales. Cfr. Caballero Samper, I. 2013.

${ }^{15}$ Cfr. Guzmán, G. 1968. La Violencia en Colombia. Parte descriptiva: 15-39 Cali: Progreso. La ciudad de Pamplona se encuentra ubicada en el departamento de Norte de Santander. Para la época objeto de estudio, la diócesis incluía parroquias de los departamentos de Santander y Norte de Santander.

${ }^{16}$ Cfr. Figueroa, H. 2007. «Clérigos y violencia en el norte de Boyacá. 1930-1946», en A. E. González (ed.), Diversidad y dinámicas del cristianismo en América Latina: 355-396. Bogotá: Editorial Bonaventuriana. Aunque versa sobre esta misma temática, no fue posible consultar la tesis de la profesora Bárbara García, debido a que la Universidad Cooperativa la guarda en un depósito y, por esa razón, no se encuentra disponible para los investigadores. García, B. 1987. De la violencia simbólica a la violencia política: el caso del Norte de Boyacá (Tesis de grado). Bogotá: Universidad Cooperativa de Colombia.

${ }^{17}$ Archivo Secreto Vaticano (en adelante ASV), A.E.S.CColombia,Pos.582_584, Fasc. 40, Secretaría de la Santa Congregación de Asuntos Eclesiásticos Extraordinarios «Situazione Politico-religiosa in Colombia», sin fecha, f. 05r; Ibídem, Giobbe a Pacelli, 15 de noviembre de 1932, f. 87r; Ibídem, Pos. 566, Fasc. 29, Giobbe a la Secretaría de Estado de Su Santidad, 21 de marzo de 1931, ff. 33r y 34r.

Hispania Sacra, LXVI

133, enero-junio 2014, 263-285, ISSN: 0018-215X, doi: 10.3989/hs.2013.053 
político-religioso en la diócesis de Pamplona (con parroquias en los departamentos de Santander y Norte de Santander) en los años treinta, para explicar sus repercusiones en la violencia anticlerical del 9 de abril de 1948, tras el asesinato del líder liberal Jorge Eliécer Gaitán. ${ }^{18}$ Según este autor, que escribe desde una perspectiva crítica con respecto a la Iglesia católica, la configuración del anticlericalismo colombiano hizo que contribuyera a la instauración de un civismo que, al igual que en España, acabó convirtiéndose en una especie de «religión alternativa», capaz de presentarse como una «opción sistémica al catolicismo de la jerarquía y la oficialidad conservadora».${ }^{19} \mathrm{En}$ los dos casos, el colombiano y el español, el anticlericalismo presentaría una coincidencia fundamental, la «desacralización de la figura del cura» como mecanismo de desprestigio para contrarrestar su influencia religiosa y, sobre todo, su implicación en el plano político ${ }^{20}$ Hay que recordar que el clero tenía a su disposición, además de la prensa religiosa y conservadora, el instrumento propagandístico más efectivo de la época: el púlpito. Esto lo convertía en la principal amenaza electoral para el liberalismo. ${ }^{21}$ En este orden de ideas cabe adelantar que, parte de la novedad y de la relevancia de la presente investigación, radica precisamente en el hallazgo de ejemplos históricos concretos, para el caso colombiano, de dicha intención de desprestigio, esto es, de la estrategia de propaganda anticlerical llevada a cabo por la policía liberal en contra de los párrocos de la diócesis de Nueva Pamplona.

Por lo demás, ante el vacío antes señalado acerca de la escasez de investigaciones sobre el papel de la Iglesia en la Primera Violencia, es necesario subrayar las dificultades que enfrenta el historiador que aborda este tipo de temáticas, especialmente en cuanto al manejo de fuentes como la prensa, los informes de las autoridades civiles, judiciales, policiales o eclesiásticas -así como los testimonios de los protagonistas -, los cuales, la mayoría de las veces obedecieron a criterios sectarios y a las vivencias y circunstancias particulares de los actores implicados. Por lo tanto, es necesario revisar dicha documentación, contrastarla y examinarla teniendo en cuenta los sesgos partidistas, como el que se denuncia

18 Cfr. Arce Fustero, G. 2005. «Anticlericalismo, secularización y violencia: algunas pautas de historia comparada entre España y Colombia (1930-1948)», en A. M. Bidegaín y J. D. Demera (comps.), Globalización y Diversidad Religiosa en Colombia: 149-166. Bogotá: Universidad Nacional de Colombia; del mismo autor: 2005. «Liberalismo y Catolicismo en Colombia: la lucha contra una “religiosidad africana"». Reflexión Política 13: 60-74. Arce Fustero, G. 2007. «El "clero politiquero"»: la consolidación de un capital simbólico excluyente», en E. A. González (ed.), Diversidad y dinámicas del cristianismo en América Latina: 397-429. Bogotá: Editorial Bonaventuriana. Álvarez Tardío, M. Villa García, R. 2013. «El impacto de la violencia anticlerical en la primavera de 1936 y la respuesta de las autoridades». Hispania Sacra 132: 683-764.

${ }^{19}$ Cfr. Ibídem, 165.

${ }^{20}$ Cfr. Ibídem, 61-62.

${ }^{21}$ Cfr. Ibídem, 409 y 425. 
en el siguiente memorando enviado al Ministerio de Gobierno en el que se describe el funcionamiento de la rama judicial en el nororiente del país durante los primeros años de la década del treinta:

«El poder judicial en aquellas provincias merece un estudio cuidadoso, pues ha llegado a parcializarse. Se puede aceptar como un hecho que un juez liberal no condena un delincuente liberal y que uno conservador tampoco sanciona a un conservador; y también que elementos importantes del poder judicial, intervienen abiertamente en política». ${ }^{22}$

Para colmo, las comunicaciones telegráficas también fueron objeto de manipulaciones, y en consecuencia los informes de orden público enviados por este medio fueron igualmente alterados, lo que hizo necesario respaldarlos con copias autenticadas enviadas a Bogotá. ${ }^{23}$ Incluso se llegó a la creación de estaciones clandestinas para dar comunicaciones falsas, al tiempo que las oficiales eran destruidas una y otra vez. ${ }^{24}$ Por consiguiente, fue necesario efectuar una comparación entre las fuentes hemerográficas y documentales, eclesiásticas y oficiales, que se ocuparon de la participación del clero en política y en la violencia. Con este fin, fueron consultados periódicos de la época, nacionales y regionales, el Archivo General de la Nación de Colombia, el Archivo Secreto Vaticano y el Archivo de la Arquidiócesis de Pamplona (Norte de Santander). Esta labor permitió contrastar el nivel de correspondencia y contradicción entre estos documentos, pero, especialmente, comprobar que constituyen, por encima de todo, una evidencia más del sectarismo. Sin embargo, un aspecto que merece de antemano resaltarse, y sobre el que nos detendremos más adelante, es la coincidencia final entre algunas investigaciones realizadas por la rama judicial (especialmente cuando se trató de jueces con comisiones especiales del gobierno de Bogotá, al fin y al cabo en cabeza del presidente Olaya y, por lo tanto, probablemente menos supeditados a los intereses de los políticos locales); y las efectuadas por las autoridades eclesiásticas, en relación con algunas de las acusaciones hechas al clero de participar en hechos violentos.

${ }^{22}$ AGN, Archivo Anexo 2, Ministerio de Gobierno, Sección 4, Justicia, Orden Público-Informes, Caja 1, Carpeta 3, Memorándum sobre situación de los Santanderes (sin fecha), f. 89.

${ }^{23}$ Ibídem, Correspondencia-Telegramas, Caja 4, Carpeta 2, Alcalde Municipal de Capitanejo al Ministro de Gobierno, 9 de julio de 1932, f. 102. Por otro lado, la honestidad de los telegrafistas fue defendida ante el Ministerio de Gobierno: «Suyo ayer. Honor explicarle: créese que envidiosos con pretextos políticos o cualesquiera otros desarrollan intrigas contra intachable personal oficina telegráfica aquí. Respetuosamente». Ibídem, Caja 5, Carpeta 1, Telegrama a Morales Olaya, 29 de enero de 1932, f. 18. Mientras tanto, los conservadores de Soatá atacaron la oficina de telégrafos para matar al telegrafista por ser liberal. Cfr. «Cómo hicieron el ataque los conservadores a la oficina de telegrafía», El Tiempo, 13 de julio de 1932, p. 12.

${ }^{24}$ Ibídem, Caja 5, Carpeta 1, Capitán Callejas al Ministro de Guerra, 25 de octubre de 1932, f. 178. 


\section{LA PRENSA COMO INSTRUMENTO DE MOVILIZACIÓN POLÍTICO-RELIGIOSA}

Los periódicos de uno y otro partido publicaron las noticias de orden público, de tal manera que en las respectivas versiones sus copartidarios eran indefectiblemente presentados como víctimas de sus enemigos políticos. El lenguaje empleado refleja la carga de emotividad que producía el sentido de pertenencia a cada una de los sectores, acompañada de imágenes descalificadoras de los oponentes.$^{25}$ En la prensa local fue aún más evidente la politización del discurso, puesto que en las áreas en conflicto la actividad periodística era concebida, fundamentalmente, como un instrumento de lucha partidista. El siguiente comentario del director del diario conservador de Málaga, Miguel Matus Gallo, ilustra el sectarismo de la prensa de provincia, y el concepto que el autor tenía de su labor:

«El semanario La Defensa es un periódico puramente político fundado para defender el partido conservador contra el liberal, y, especialmente para defender a los campesinos conservadores del cúmulo de atropellos e inequidades de que han sido víctimas por parte de los funcionarios del gobierno que preside el señor Olaya Herrera. [...] Si el abuso y la iniquidad que aquí imperan como sistema de gobierno no encuentra remedio en las altas esferas oficiales, no me queda otro camino que el de acudir al tribunal de la opinión pública para obtener al menos la sensación de la reprobación general». ${ }^{26}$

Más adelante, Matus Gallo señalaba que su periódico también se encargaba de divulgar el ideario católico para contrarrestar la difusión del protestantismo promovido por el gobierno liberal. En este orden de ideas, la prensa conservadora denunciaba exclusivamente las persecuciones perpetradas en contra de sus copartidarios y del clero ${ }^{27}$ Por consiguiente, al tener la Iglesia y sus aliados toda una empresa editorial a su servicio, ${ }^{28}$ no es de extrañar que la destrucción de las imprentas fuera un ingrediente más de la lucha partidista, como ocurrió con $E l$ Deber de Tunja y La Unión Católica de Bucaramanga. ${ }^{29}$

La prensa liberal, por su parte, también asumió el proselitismo en defensa de su partido y denunció al clero politizado, al que acusaba de traicionar su misión

${ }^{25}$ Cfr. Acevedo Carmona, D. 2003. «Prensa y confrontación política en Colombia, 1930-1954», en VV.AA., Medios y nación: historia de los medios de comunicación en Colombia. Memorias de la VII Cátedra Anual de Historia Ernesto Restrepo Tirado: 282-316. Bogotá: Aguilar; Acuña, O. Y. 2007. «Comunicación y violencia. Una mirada desde las elecciones en Boyacá, 1930-1953». Historia Caribe 12: 77-90.

${ }^{26}$ Archivo Arquidiócesis de Pamplona, [en adelante AAP], Copiadores, Caja 12, Libro 1, Copiadores de Comunicaciones del Señor Afanador, Afanador a Giobbe, 27 de septiembre de 1933, ff. 8 y 9.

27 «Fue atacado a bala el párroco de Cucutilla», El País, 27 de julio de 1933,p. 1.

${ }^{28}$ Cfr. Silva, R. 2004. «Relación de imprentas y tipografías en Colombia». Sociedad y Economía 6: 159-171.

${ }^{29}$ AGN, Archivo Anexo 2, Ministerio de Gobierno, Sección 4, Justicia, Orden Público-Informes, Caja 1, Carpeta 3, Ministro de Gobierno al Ministro de Guerra, 26 de julio de 1932, f. 26. 
pastoral. Por ejemplo, en Vanguardia Liberal de Bucaramanga se hicieron las siguientes acusaciones:

«En García Rovira, el asalto a mano armada en las poblaciones, la matanza en las veredas y el asesinato en los caminos y encrucijadas obedece al sectarismo criminal de algunos párrocos empeñados en crear el problema religioso entre nosotros, para así servirse de la ignorancia y fanatismo de los campesinos, en el exterminio que ellos predican contra el liberalismo». ${ }^{30}$

El Tiempo, principal periódico liberal de Bogotá, eventualmente publicó noticias en defensa de sacerdotes proliberales,,$^{31}$ o sobre quienes por su moderación y sus condenas a la violencia antiliberal terminaron por granjearse la animadversión de los conservadores. Este fue el caso del Padre Aldana, con quien «los conservadores de Manta estaban disgustados por algunos sermones que pronunció últimamente criticando sus actuaciones salvajes, así como las de otros sacerdotes».32 Ocasionalmente, esta publicación reprodujo las respuestas de algunos de los denunciados en este mismo impreso por ejercer un proselitismo pro conservador, como sucedió con el párroco de Arbeláez, Guillermo Garavito, quien aseguraba que precisamente gracias a sus intervenciones desde el púlpito se habían alcanzado «completas garantías para el adversario». ${ }^{33}$

Las versiones contradictorias permiten comprender la confusión y el desconcierto de las autoridades civiles y eclesiásticas de la capital del país y de algunos departamentos, frente a la situación de orden público en las zonas rurales, y muy especialmente acerca de la participación política del clero. La generalizada crisis informativa se vio empeorada por otros elementos: la sospecha y el rumor, que, como si de cacería de brujas se tratara, incitaban a todo tipo de acusaciones, retaliaciones y venganzas. ${ }^{34}$ Este fenómeno, en su conjunto, explica en buena parte no sólo el recrudecimiento de los hechos violentos, sino también la situación de la Iglesia en este contexto: primero, en cuanto al sentimiento exagerado del clero de sufrir una persecución religiosa comparable a la de México durante las Guerras Cristeras en ese mismo período, o en la Unión Soviética desde años

\footnotetext{
${ }^{30}$ «El problema religioso y el político de García Rovira.- La conducta criminal del párroco Jordán.Un memorial al Presidente y al Nuncio Apostólico», Vanguardia Liberal, 30 de abril de 1932, pp. 1 y 3. Cfr. Arce Fustero, G. 2007:420-425.

${ }^{31}$ «Se temen que ocurran varios desastres en el barrio La Playa. El Padre Carrasquilla amenazado», El Tiempo, 2 de noviembre de 1933, p. 6: «Por medio de pasquines, escritos en la pared de la iglesia, los conservadores amenazan al padre Carrasquilla, por el sólo hecho de pertenecer, sin ninguna hipocresía, a la causa liberal».

32 «Los conservadores atacaron a bala la casa cural de Manta», El Tiempo, 15 de enero de 1931, p. 15; «Cómo hicieron el ataque los conservadores a la oficina de la telegrafía: insultaron soezmente al párroco que los llamaba al orden», El Tiempo, 13 de julio de 1932, p. 12.

33 «Habla el cura párroco de Arbeláez», El Tiempo, 18 de abril de 1931, p. 6.

${ }^{34}$ Sánchez, G. 1991: 18.
} 
anteriores; y segundo, al incidir en la variedad de versiones sobre su papel en la política, especialmente en la difusión de las imágenes de sacerdotes disparando desde los campanarios de las iglesias, y de las casas curales convertidas en parques de armas ${ }^{35}$ Esta situación llevó a que la construcción simbólica de «el otro» se constituyera en un elemento esencial del conflicto político-religioso durante la Violencia. A la larga, ni las hostilidades a la Iglesia tenían las dimensiones que la sensibilidad de los católicos les achacaba; ni eran ciertas todas las acusaciones contra los párrocos, especialmente en cuanto a su participación directa en hechos violentos durante este período. Estas ideologizaciones son explicadas, para el caso español, por Jon Juaristi, quien afirma que las críticas anticlericales a lo largo de la historia han obedecido a estereotipos sobre el clero que, como tales, contienen tanto elementos imaginados y proyectados con fines partidistas como otros con base en la realidad.$^{36}$ Caro Baroja, por su lado, se refiere también a las «acusaciones estereotipadas», esto es, cuando «las sociedades crean sus arquetipos y modelos, es claro que luego los aplican de modo bastante mecánico, dejándose llevar por el runrún, sonsonete y siguiendo la línea del menor esfuerzo...». ${ }^{37}$ Veamos ahora casos concretos que muestren cómo se reproducían estos estereotipos en Colombia en los años treinta del siglo pasado.

DENUNCIAS SOBRE EL PROSELITISMO DEL CLERO: VERSIONES CONTRADICTORIAS DE LA PRENSA, LAS AUTORIDADES CIVILES, MILITARES Y ECLESIÁSTICAS

En las décadas del veinte y del treinta, el clero recibió enérgicas y reiteradas acusaciones por parte de los liberales, de intervenir en política y participar directamente en hechos violentos, al tiempo que los conservadores y la jerarquía las negaban con la misma vehemencia. En la medida en que dichas denuncias provinieron principalmente de fuentes de un solo partido - las mismas que la historiografía al uso sobre la Primera Violencia cita hasta la fecha,$-{ }^{38}$ es necesario

${ }^{35}$ Cfr. Navarro, J. 1998. «La invención de la sospecha», en C. Castillo del Pino (comp.), La Sospecha: 33-40. Madrid: Alianza Universidad; Castillo del Pino, C. 1998. «Sospecha, suspicacia, paranoia», en Ibídem, 11-32. Navarro explica cómo la sospecha, aunque surja de indicios vehementes, «siempre es imaginación, invención, suposición...». No es extraño entonces, que este fenómeno contribuyera en medio del despliegue de la propaganda anticlerical, a la propagación de acusaciones de esta índole. En este sentido, Arce Fustero se refiere a las imágenes de curas que disparaban desde sus casas o «desde su residencia o desde los campanarios de las iglesias», así como al «mito de los almacenes en los conventos y los monasterios repletos de armas con las que atacar a los liberales...». Cfr. Arce Fustero, G. 2005: 67; Ibídem, 2007: 410 y 420.

${ }^{36}$ Juaristi, J. 2008. «Prólogo», en J. Caro Baroja, Historia del anticlericalismo español: 15. Madrid: Caro Raggio Ed.

${ }^{37}$ Caro Baroja, J. 2008: 15 y 235.

${ }^{38}$ A manera de ejemplo, el historiador Javier Guerrero explica, en uno de los apartados de su libro, la intervención del clero politizado e implicado en episodios violentos contra los liberales, mediante un 
ampliar y contrastar diversos tipos de documentación para lograr interpretaciones más elaboradas y comprender hasta qué punto, tanto las denuncias contra el clero como la defensa del mismo, de origen liberal y conservador, respectivamente, estuvieron supeditadas, en buena parte, a las estrategias propagandísticas y electorales del bipartidismo.

Por consiguiente, los dos ejemplos que se presentan a continuación, articulan la implicación de la Iglesia en la violencia y los mecanismos de difusión del imaginario anticlerical por parte del liberalismo: el primero, ocurrido en San José de Avila, y el otro, en Chinácota, dos poblaciones del departamento de Norte de Santander, ambas pertenecientes a la diócesis de Nueva Pamplona. La idea, como se mencionó anteriormente, es destacar las diferencias existentes en la documentación consultada procedente de intereses políticos opuestos. Por lo tanto, se tuvieron en cuenta fuentes de prensa así como archivos públicos y eclesiásticos. En general, la investigación histórica sobre las acusaciones al clero politiquero cuenta, primero que todo, con las versiones de la prensa liberal y conservadora; $\mathrm{y}$, en menor medida, con los documentos de los archivos eclesiásticos en que se plasman los pronunciamientos al respecto. Sin embargo, para los dos casos, el de San José de Ávila y Chinácota, es posible consultar los resultados de las investigaciones del juez de policía Mateo Franco, encargado por el gobierno nacional de indagar sobre la responsabilidad de estos párrocos en incidentes violentos. Esta particularidad, relativa a la existencia de dicha documentación, permite añadir nuevos elementos para la comprensión de este fenómeno.

\section{CLERO, POLÍTICOS, JUECES Y POLICÍAS EN LA DIÓCESIS DE NUEVA PAMPLONA}

Primer caso: Los liberales aseguran que en la casa cural de San José de Ávila la policía decomisó un parque de armas...

Al padre Guarín, párroco de San José de Ávila, lo culpaban de incitar con sus sermones a los conservadores a perpetrar ataques, incendios y asesinatos en contra de los liberales, y de enseñarles a sus fieles que matar liberales no era pecado. ${ }^{39}$ Así mismo, fue acusado de hacer giras políticas antigobiernistas, «con discursos que exaltaban los ánimos», ${ }^{40}$ y de ser el principal instigador del ataque

solo caso, el del padre Nepomuceno Goyeneche, extraído a su vez de una sola fuente, El Tiempo, periódico liberal de Bogotá. Cfr. El Tiempo, 22 de enero de 1933, p. 4, cit. por Guerrero, J. 1991: 110-111.

39 AGN, Archivo Anexo 2, Ministerio de Gobierno, Sección 4, Justicia, CorrespondenciaTelegramas, Caja 5, Carpeta 2, Felipe Pérez a Olaya Herrera, julio (ilegible) de 1932, f. 95; Ibídem, Gobernación de Norte de Santander al Ministro de Gobierno, 26 de octubre de 1932, f. 145.

${ }^{40}$ Ibídem, Caja 3, Carpeta 3, Gobernación de Norte de Santander al Presidente de la República y al Ministro de Gobierno, 6 de julio de 1932, ff. 78 y 79.

Hispania Sacra, LXVI

133, enero-junio 2014, 263-285, ISSN: 0018-215X, doi: 10.3989/hs.2013.053 
a un retén en el que habían sido asesinados tres agentes de policía. ${ }^{41}$ Mientras que la prensa liberal criticaba su actividad proselitista a favor del partido conservador, los periódicos de este partido desvirtuaban tal información «pues no podemos aceptar que se lance sobre un ministro del altar semejante gravamen calumnioso...». ${ }^{42}$

Pero el asunto del padre Guarín excedió las cotidianas controversias periodísticas para pasar a manos de la justicia, dada la gravedad de las denuncias en su contra. El Encargado de Negocios de la Santa Sede, con el fin de evitar que lo tomaran preso, le recomendó que huyera a Pamplona o a Bogotá, donde podría defenderse. Sin embargo, el obispo de Pamplona, Rafael Afanador, consideró innecesario atender a tal sugerencia:

«Pláceme informar a V. E. que Pbro. Guarín está aquí en retiro con demás sacerdotes hace siete días, y ataque fue antier (sic.). Convendría que pidieran pruebas al director Aza. Mes pasado informe acusación semejante; pedile pruebas y no diolas (sic.); eran mentiras. Excmo. Presidente República recibió queja, hace 30 días, de las señoras de Sepulturas, sobre las inmoralidades repetidas por individuos de la policía; pero esto no lo oyen». ${ }^{43}$

Cuando las autoridades intentaron capturar al sacerdote las autodefensas conservadoras atacaron a la escolta de la Policía Nacional ${ }^{44}$ Ante tal situación, el Ministro de Gobierno dio órdenes de abstenerse de capturar a Guarín puesto que, además de impopular, dicha medida tendría consecuencias que agravarían la situación de orden público en el departamento; y ya que, sin las previas formalidades, resultaba contraria al Concordato..$^{45}$ Las autoridades departamentales lamentaron

${ }^{41}$ Ibídem, Caja 5, Carpeta 2, Dirección Nacional de la Policía al Ministro de Gobierno, 11 de noviembre de 1932 , ff. 170 y 171.

42 «Del párroco Guarín», El Porvenir, 21 de diciembre de 1932.

43 AAP, Copiadores, Caja 10, Libro 1, Comunicaciones, Afanador al Encargado de Negocios de la Santa Sede, 16 de noviembre de 1932, f. 981; ASV, A.E.S. Colombia, Pos. 564, Fasc. 24, Pacelli a Giobbe, 14 de noviembre de 1932, f. 86r. Es importante destacar que, incluso las esposas de los liberales, eran proclives a mantener y demostrar su lealtad al clero. María del Pilar Salomón Chéliz cuenta cómo los anticlericales españoles de finales del siglo XIX y comienzos del xx explicaban con argumentos machistas la docilidad de los niños frente al control de la Iglesia, resultado de una virilidad débilmente desarrollada, al entender que lo «viril» representaba la presencia de cualidades como la decisión y la capacidad individual, en contraste con las características femeninas. Desde este punto de vista, se suponía comprensible el hecho de que las mujeres fueran vulnerables a la predicación clerical. Salomón Chéliz, M. P. 2002. «El discurso anticlerical en la construcción de una identidad nacional española republicana (1898-1936)». Hispania Sacra 54: 491. De la misma autora: 2006. «Laicismo, género y religión: perspectivas historiográficas» Ayer 61: 291-308; 2005. «Las mujeres en la cultura política republicana: religión y anticlericalismo». Historia Social 53: 103-118.

44 AGN, Archivo Anexo 2, Ministerio de Gobierno, Sección 4, Justicia, CorrespondenciaTelegramas, Caja 5, Carpeta 2, Cuervo a Morales Olaya, 11 de noviembre de 1932, ff. 157 y 158.

${ }^{45}$ Ibídem, Ministro de Gobierno al Ministro de Relaciones Exteriores (Urdaneta Arbeláez), 14 de noviembre de 1932 , f. 155 . 
esta prudencia puesto que consideraban que su detención era una condición necesaria para la pacificación de la región..$^{46}$ Además, para ellas, los argumentos en su contra quedarían posteriormente confirmados ante una nueva acusación: la de encontrarse armas e individuos revoltosos refugiados en la casa cural. ${ }^{47}$

Sobra decir que también en esta ocasión, y como era costumbre, la versión oficial y la de los periódicos liberales difirió por completo de la presentada por la prensa conservadora, según la cual, el padre se había limitado a procurar auxilios espirituales a las víctimas de un ataque de la policía, por lo que había sido agredido y maltratado por las autoridades, quienes durante la requisa habían incurrido en actos sacrílegos, «con actitud diabólica», contra los objetos religiosos. De esta manera, no era un parque de armas ni tampoco malhechores refugiados lo que se había encontrado en la casa cural, sino algo muy distinto: una escopeta mohosa, un diputado conservador de Ocaña y un vecino recogiendo una carga de arvejas. ${ }^{48}$

Por otro lado, entre los detenidos en la jornada estuvo Roque Figueredo, quien al ser sometido a interrogatorio confesó haberle robado un fusil a un policía ebrio y habérselo entregado al padre Guarín. El Ministro de Gobierno le pidió al sacerdote una aclaración, ${ }^{49}$ a lo que el presbítero respondió que se trataba de nuevas calumnias sonsacadas por coacción:

«Extraño declaración Figueredo quien procedió coacción oficial. Declaro no he recibido arma ninguna. Policía practicome (sic.) requisa casa cural, iglesia violando domicilio ultrajándome, amenazándome inicuamente. Peligró mi vida, vime precisado abandonar parroquia, como hízolo vicario Salazar, presbítero de Cala. Diputado Arévalo, quien hayábase (sic.) conmigo, puede confirmar mi acerto (sic). Solo (sic). pasión política informa actuaciones policía. Mis feligreses abandonan sus fincas falta garantías. Salúdolo respetuosamente. Guarín Presbítero»..$^{50}$

Sin embargo, mientras el gobierno recibía estas explicaciones, el comandante de la Policía Nacional, Gustavo Gómez, insistía en corroborar la versión de los hombres bajo su mando. Negaba que la policía hubiera ultrajado

${ }^{46}$ Ibídem, Pablo Aza al Ministro de Gobierno, 12 de noviembre de 1932, f. 172.

${ }^{47}$ Ibídem, Cuervo al Presidente y al Ministro de Gobierno, 4 de marzo de 1933, f. 227.

${ }^{48}$ Ibídem, Orden Público-Informes, Caja 1, Carpeta 3, «Escándalo farisaico del liberalismo por lo de San José de Ávila. Cómo pasaron las cosas. Qué elementos bélicos le encontraron al Párroco. A quiénes capturó la Policía» (recorte de un periódico conservador en el que no se incluye el nombre del mismo), 19 de marzo de 1933, f. 157. Sobre la reiterada acusación al clero de convertir la casa cural en «madriguera de malhechores» como instrumento de propaganda anticlerical, ver, por ejemplo: «Atentados conservadores en Chinavita», El Tiempo, 5 de febrero de 1931.

${ }^{49}$ Ibídem, Correspondencia-Telegramas, Caja 5, Carpeta 2, Dirección de la Policía Nacional al Ministro de Gobierno, 9 de marzo de 1933, f. 229; Ibídem, Morales Olaya a Guarín, 10 de marzo de 1933, f. 232.

${ }^{50}$ Ibídem, Guarín a Morales Olaya, 12 de marzo de 1933, f. 233.

Hispania Sacra, LXVI

133, enero-junio 2014, 263-285, ISSN: 0018-215X, doi: 10.3989/hs.2013.053 
al sacerdote, puesto que «tanto para el Padre Guarín como para sus feligreses Policía da toda clase garantías...». ${ }^{51}$ Por su parte, la Asamblea Departamental de Norte de Santander interpuso ante el nuncio Paolo Giobbe una solicitud para la remoción de Guarín y propuso como solución la medida que desde el punto de vista electoral más le convenía al liberalismo: aumentar el cuerpo de Policía Nacional «que tan eficaz servicio ha prestado al departamento». ${ }^{52}$

El obispo Afanador hizo saber al padre Guarín las quejas que llegaban a su despacho, y le ordenó no emitir opinión alguna sobre la policía o el gobierno, lo mismo que evitar que el pueblo se involucrara en dificultades y episodios violentos. ${ }^{53}$ Aunque al Nuncio le parecía difícil admitir la verdad de tales acusaciones, consideró necesario dar paso a una investigación; ${ }^{54}$ además, ante la desorientación reinante, pensó que sería apropiado enviar a un eclesiástico autorizado con el fin de que investigara la verdadera situación del clero y la política en la diócesis de Pamplona, y de esta manera, pudiera elaborar un informe digno de crédito. En principio, su candidato fue el Arzobispo de Bogotá, pero el Vaticano consideró inoportuno el nombre de Perdomo para esta misión, primero, porque sería dar «mucha importancia al asunto»; y luego, por los resquemores que podría despertar en el gobierno. ${ }^{55}$ Guarín, por su lado, ofreció desmentir públicamente las denuncias en su contra, e insistió en que se había limitado a criticar los escándalos protagonizados por la policía, de los cuales las señoras de la localidad ya se habían quejado ante el presidente de la república. Mientras tanto, un grupo de feligreses dirigió a Mons. Afanador otra defensa del párroco. Después de exaltar su labor pastoral, los firmantes explicaron la causa de las calumnias en su contra: su enfrentamiento con el gamonal de la región, quien aprovechaba su posición para ejercer un monopolio comercial y explotar a los campesinos. ${ }^{56}$

El Tribunal Eclesiástico, por su parte, solicitó insistentemente a la policía las pruebas contra Guarín, pero nunca las recibió. ${ }^{57}$ Por lo tanto, resolvió suspender

${ }^{51}$ Ibídem, Gómez al Ministro de Gobierno, 16 de marzo de 1933, ff. 234 y 235.

52 «La Asamblea Departamental del Norte de Santander y el cura Guarín», Vanguardia Liberal, 9 de marzo de 1933, p. 1.

${ }^{53}$ AAP, Copiadores, Caja 10, Libro 1, Comunicaciones, Afanador a Guarín, 13 de enero de 1933, f. 984. Recomendaciones similares, ordenadas por el Nuncio, en: ASV, A.E.S. Colombia, Pos. 564, Fasc. 24, Mons. Giobbe a Mons. Afanador y Cadena, 19 de diciembre de 1931, f. 20r.

${ }^{54}$ AAP, Nunciatura-Santa Sede, Caja 1, Carpeta 1, Giobbe a Afanador, 7 de marzo de 1931, sin foliación.

${ }_{55}$ ASV, A.E.S. Colombia, Pos. 564, Fasc. 24, Giobbe a la Secretaría de Estado de Su Santidad, 3 de mayo de 1932, f. 30r; Ibídem, Secretaría de la Santa Congregación de Asuntos Eclesiásticos, Colombia: Lotte politiche. Accusa contro il clero, 3 de julio de 1932, ff. 47r y 47v.

${ }^{56}$ AAP, Pro clero, Libro 7, Carta de ciudadanos católicos de Cáchira a Afanador, 14 de octubre de 1933, f. 15. Sobre las diversas facetas del liderazgo ejercido por el clero en las comunidades rurales durante esta época, Cfr. Figueroa, H. 2007: 361-362.

${ }^{57}$ «Borrasca en la Asamblea», La Unidad Católica, 9 marzo de 1933, p. 207.

Hispania Sacra, LXVI 133, enero-junio 2014, 263-285, ISSN: 0018-215X, doi: 10.3989/hs.2013.053 
cualquier sanción hasta que estas fueran presentadas ${ }^{58}$ Sin embargo, las investigaciones judiciales que sí continuaron, finalmente encontraron falsas las imputaciones hechas contra el sacerdote, razón por la cual, el Nuncio le solicitó al obispo Afanador que se levantaran demandas por calumnia:

«Me alegro vivamente en ver confirmada con pruebas legales mi íntima convicción de que se trataba de mera calumnia. Estimo por lo tanto necesario dar a este resultado la mayor publicidad posible. Además, no obstante yo tenga la seguridad de que, como afirma V. E., intentar un juicio por calumnia tendría resultado nugatorio en cuanto que no se procedería a imponer pena alguna a los detractores, creo sin embargo que tal juicio sería siempre de algún provecho, porque siempre procuraría molestias a los calumniadores, los obligaría, probablemente, a gastar dinero (cosa no muy agradable), dejaría en actos oficiales constancia de la inocencia del párroco y quizá nos serviría también para disminuir un poco tales calumnias en el porvenir. Por estas razones me permito insistir en la necesidad de promover un juicio»..$^{9}$

Así mismo, Giobbe aprobó la idea del Obispo de pedir al gobernador de Norte de Santander, el político conservador Luis Augusto Cuervo, pruebas de los cargos contra el clero, o en su defecto, una retractación pública sobre los mismos..$^{60}$

Segundo caso: Los liberales aseguran que en medio de una balacera salieron disparos de la torre de la iglesia de Chinácota...

En la plaza de Chinácota, Norte de Santander, después de una balacera, los liberales afirmaron que habían salido disparos de la torre de la iglesia, y muchos exigieron el encarcelamiento del párroco, el padre Castillo. ${ }^{61}$ Esta versión fue pronto desmentida por el obispo de Pamplona. ${ }^{62}$ También en este caso, las señoras del pueblo escribieron una carta a El Tiempo para defender al sacerdote de las denuncias que amenazaban con su posible detención y encarcelamiento ${ }^{63}$ Aunque los primeros informes del gobernador Cuervo insistieron en la versión acerca de los tiros desde la torre de la iglesia, posteriormente este afirmó que

${ }^{58}$ AAP, Copiadores, Caja 10, Libro 1, Comunicaciones, Afanador a Restrepo (Vicario General de Bogotá), 16 de enero de 1933, f. 988.

${ }^{59}$ Ibídem, Nunciatura-Santa Sede, Caja 1, Carpeta 1, Giobbe a Afanador, 10 de abril de 1933, sin foliación.

60 Ídem.

61 «La cárcel para el cura de Chinácota», La Unidad Católica, 11 de febrero de 1933, p. 135.

62 AGN, Archivo Anexo 2, Ministerio de Gobierno, Sección 4, Justicia, CorrespondenciaTelegramas, Caja 5, Carpeta 1, Andrés Restrepo Sáenz a Morales Olaya, 10 de febrero de 1933, f. 235; Ibídem, Cuervo al Ministro de Gobierno, 5 de febrero de 1933, f. 246; Ibídem, Gómez al Ministro de Gobierno, 6 de febrero de 1933, f. 251.

${ }^{63}$ «La actuación del cura de Chinácota fue de conciliación», El Tiempo, 9 de febrero de 1933, p. 6. 
el padre le había dejado una magnífica impresión, tras declarar «ser amigo y defensor del gobierno, y trabajar por el respeto y el apoyo a la autoridad». ${ }^{64}$ Finalmente, el ministro de gobierno Agustín Morales Olaya (miembro del partido conservador y primo del presidente de la república), recibió un informe detallado del juez de policía Mateo Franco, que desvelaba los abusos de las autoridades en García Rovira y su directa responsabilidad en los acontecimientos de Chinácota:

«El lunes 6 de febrero del año en curso, manifestó el comandante Jaramillo de la Policía Nacional en Cúcuta, estando en su despacho, su extrañeza por el número «exiguo» de muertos y heridos del día anterior en Chinácota, ya que tenían consignas y órdenes terminantes de «tirar a bulto», como dice él, y sin embargo habían quemado doscientos setenta y siete cartuchos y los muertos y heridos no alcanzaban, o no correspondían al número de cartuchos quemados. Esto originó que el mismo comandante Jaramillo le hiciera saber al sargento Aguilar Ariza que por cada disparo que se hiciera al aire, el impondría una multa de dos pesos, pues debían disparar sin compasión sobre cada individuo». ${ }^{65}$

A continuación, el juez Franco se refirió a los sucesos de San José de Ávila, en donde, como vimos, el párroco Guarín había recibido acusaciones similares:

«El sargento Ariza quemó más de cuatrocientos cartuchos disparando sobre una casa en San José de Ávila, en donde decomisó una escopeta de cacería, y para justificar su conducta, dijo haber capturado, en la casa del cura Guarín, una cuadrilla de bandoleros y decomisado un parque completo». ${ }^{66}$

Franco llegó a la conclusión de que las denuncias en contra de los sacerdotes Guarín y Castillo eran completamente falsas. Igualmente, responsabilizó a las autoridades, y en concreto a la policía, de suscitar los tiroteos y los montajes con los que después pretendían inculpar a los párrocos, acusados de convertir las casas curales en refugio de bandidos y de armamento, y de dispararles a los liberales desde las iglesias.

No obstante, meses después, el comandante Gustavo Gómez aseguraba al Ministro de Gobierno que el informe del juez Franco sobre los hechos de Chinácota exageraba la responsabilidad de la policía. ${ }^{67} \mathrm{Y}$ no faltaban quienes argumentaban que las investigaciones de Franco habían omitido expresamente el testimonio de los policías acusados. Llegados a este punto, surge la pregunta acerca de la filiación partidista de dicho juez; sin embargo, hasta ahora no hemos

64 AGN, Archivo Anexo 2, Ministerio de Gobierno, Sección 4, Justicia, CorrespondenciaTelegramas, Caja 5, Carpeta 1, Cuervo al Ministro de Gobierno, 20 de febrero de 1933, f. 229.

${ }^{65}$ Ibídem, Orden Público-Informes, Caja 1, Carpeta 3, Franco a Morales Olaya, 17 de abril de 1933, ff. 222-223.

${ }^{66}$ Ídem.

${ }^{67}$ Ibídem, Gómez al Ministro de Gobierno, 26 de junio de 1933, ff. 215 y 216. 
encontrado información a este respecto, y no sería para nada de extrañar que se tratara de un conservador, puesto que vale la pena recordar que para entonces, la rama judicial estaba, en buena parte, en manos de dicho partido; ${ }^{68}$ lo que por otra parte, dado el caso, tampoco supondría, al menos no necesariamente, que sus conclusiones fueran falsas. Lo cierto es que, en su momento, las averiguaciones de éste y de otros jueces encargados de casos similares, merecieron la plena confianza del gobierno de Olaya, puesto que fueron razón suficiente para que finalmente se determinara la aplicación de nuevas estrategias de orden público, tal como lo demuestra la solicitud hecha por el ministro de gobierno, Agustín Morales, al comandante Gómez, para suspender las comisiones de policía en aras de evitar nuevos altercados:

«Creo mi deber llamar la atención de Ud. hacia ciertos procederes de la Policía Nacional que le viene creando verdadera animadversión a ese cuerpo, especialmente en el Norte de Santander, en donde por ejemplo, se le culpa de ser la responsable de los sucesos sangrientos ocurridos en Chinácota el 5 de febrero último, culpabilidad que viene a quedar confirmada con el informe que he recibido del Juez Investigador que actúa en esa región [...] Quizá convendría el ensayo de hacer cesar por un tiempo esas rondas y comisiones para ver si en esa forma se consigue apaciguar los ánimos por demás exaltados de los ciudadanos del Norte de Santander y de García Rovira». ${ }^{69}$

De esta manera, Gómez no tuvo más remedio que proceder a un paulatino cambio en las tareas asignadas a la policía en la región del nororiente para evitar su contacto con la población civil. Así mismo, le escribió al juez Franco para que, en clave, le transmitiera los nombres de los agentes que estaban involucrados en los «desgraciados acontecimientos de Chinácota». ${ }^{70}$ Con esto, además, el gobierno terminaba por darle la razón - al menos parcial y temporalmente - a las recomendaciones del arzobispo de Bogotá, Ismael Perdomo quien, de tiempo atrás, y con base en los informes de los obispos de la región, había aconsejado el «cambio de las autoridades departamentales» para conseguir la pacificación. ${ }^{71}$ Es evidente que la demora del gobierno central en promulgar estas disposiciones, seguramente fue resultado de los informes contradictorios recibidos por largo tiempo, aunque cabe preguntarse sobre su verdadero alcance, puesto que, una vez empezaron a implementarse, las autoridades liberales a nivel local se quejaron de la anarquía suscitada por la ausencia de la policía en sitios donde la situación de orden público era crítica.

\footnotetext{
${ }^{68}$ Guerrero, J. 1991: 187-192.

${ }^{69}$ Ibídem, Morales Olaya a Gómez, marzo de 1933, f. 217.

${ }^{70}$ Ibídem, Correspondencia-Telegramas, Caja 5, Carpeta 1, Gómez a Franco, 7 de marzo de 1933, f. 262.

${ }^{71}$ Ibídem, Orden Público-Informes, Caja 1, Carpeta 3, Perdomo a Morales Olaya, 17 de diciembre de 1931, f. 1.
}

Hispania Sacra, LXVI

133, enero-junio 2014, 263-285, ISSN: 0018-215X, doi: 10.3989/hs.2013.053 


\section{Conclusiones}

Ejemplos como los anteriores demuestran varias cosas: ante todo, ponen en evidencia una de las formas empleadas por el liberalismo en las zonas ruarales para contrarrestar la injerencia proselitista del clero a favor de los conservadores, es decir, a través de montajes que involucraban a algunos párrocos del nororiente del país en episodios violentos, y que, dados los resultados de las investigaciones encontradas en los archivos consultados, probablemente no fueron otra cosa más que calumnias. Este tipo de descubrimientos constituye un ejemplo típico del anticlericalismo entendido como una corriente cultural cuyas raíces, para el caso católico, pueden rastrearse hasta el Bajo Medioevo; éste adquiere rasgos particulares en la época contemporánea ${ }^{72}$ y presenta, como uno de sus objetivos fundamentales, la intención de disminuir o eliminar la intervención de la Iglesia en el ámbito público.

Ya hemos visto cómo la promoción de la propaganda en contra del clero por su indebida participación en política es una de las características esenciales del anticlericalismo y que Caro Baroja, entre otros, plantea que dicha propaganda construye estereotipos a partir de hechos reales y de otros ficticios, convertidos en parte del folclor popular. En este sentido, los casos expuestos demuestran que, si bien fue evidente el compromiso de los párrocos del lado conservador, por otro lado, buena parte de su fama de intervenir en situaciones violentas fue producto de los mecanismos empleados por la policía liberal, en complicidad con las autoridades locales de ese partido, para difamarlos, y de esta forma, minar el alcance real del proselitismo eclesiástico. Este tipo de conclusiones invitan, por tanto, a que la investigación histórica supere la prolongación de este tipo de estereotipos, tanto de aquellos que el liberalismo tenía sobre el clero, como también los que la Iglesia y los conservadores tenían sobre los liberales. ${ }^{73}$ A su vez, es importante subrayar que el objeto del presente análisis representa la confirmación de uno de los elementos esenciales de la violencia bipartidista, relativo a las debilidad estructural de la democracia colombiana, como resultado de la parcialidad de la justicia, la politización y la actuación criminal de elementos de la fuerza pública, en complicidad con los políticos bajo cuyas órdenes actúan, con la consecuente impunidad y deterioro social. ${ }^{74}$

${ }^{72}$ Caro Baroja, J. 2008: 19-33.

73 Sobre la forma cómo liberales y conservadores asumían y entendían su identidad partidista y la de sus contrarios, Cfr. Acevedo Carmona, D. 1995. La mentalidad de las élites sobre la violencia en Colombia (1936-1949): 33-57 Bogotá: Áncora editores.

${ }^{74}$ Por las afinidades que se encuentran en cuanto a la forma como las autoridades, en primera instancia locales y luego provinciales, se veían involucradas por omisión, y en ocasiones de forma directa, 
Por último, en cuanto al enfoque y la metodología cabe todavía decir unas palabras al considerar que la ruta que proponemos resulta indispensable en aras de matizar las generalizadas interpretaciones acerca del conflicto políticoreligioso durante la violencia bipartidista colombiana de los años treinta. Tal conflicto, unas veces ignorado, otras, interpretado de forma sesgada, producto de la consulta de documentos provenientes de un solo partido o de un único tipo de fuentes (casi siempre de la prensa política), y de enfoques tendientes a desconocer algunas de las características propias de este período, tales como el papel del proselitismo clerical y anticlerical. En este sentido, hay que señalar que no sólo son pertinentes indagaciones orientadas a la comparación y al cotejo con el fin de solventar este vacío sino que, sobre todo, hay que rescatar los informes de los jueces encargados de realizar las investigaciones sobre hechos de esta índole. En este orden de ideas, sería interesante el descubrimiento de procesos que mostraran diferentes resultados, ya fuera incriminando al clero o, en su defecto, a las autoridades liberales, civiles o de policía. No obstante, hay que tener en cuenta las dificultades para su hallazgo, ya que los expedientes en que estas últimas estaban implicadas, solían ser sustraídos para encubrir a los responsables; y no cabe duda de que la desaparición de estos documentos hace aún más complicada la labor de los historiadores. A este tipo de situaciones se refirió el juez de la Policía Nacional de Málaga, Pablo Navia Carvajal, encargado de investigar las acusaciones hechas al padre Colmenares de San Andrés, similares a las de Guarín y Castillo. Según el informe enviado al Ministerio de Gobierno por dicho funcionario, el sacerdote era inocente y los resultados de sus pesquisas eran «un verdadero desastre para el alcalde y la Policía Nacional», por lo que añadió, sin ningún reparo: «haré lo imposible para ver de mejorarlo, y en todo caso no saldrá fácilmente de mis manos. Es este un expediente que, como el de Capitanejo, deberían robárselo». ${ }^{75}$ En este orden de ideas, y en la medida de lo posible, sería importante descubrir las inclinaciones políticas y religiosas de los funcionarios judiciales encargados de estas pesquisas y la forma cómo estas pudieron incidir en sus investigaciones. Todo esto con el ánimo de aportar cada vez más información que ayude a esclarecer esta realidad bastante desconocida y, por demás, compleja.

\footnotetext{
en la persecución anticlerical en España, antes de Guerra Civil (1936-39), Cfr. Álvarez Tardío, M. Villa García, R. 2013: 710-720.

${ }^{75}$ AGN, Archivo Anexo 2, Ministerio de Gobierno, Sección 4, Justicia, Orden Público-Informes, Caja 1, Carpeta 1, Navia al Director General de la Policía Nacional, 18 de septiembre de 1932,f. 149.
} 
BIBLIOGRAFÍA

\section{Archivos consultados}

Archivo General de la Nación de la República de Colombia, Archivo Anexo 2, Ministerio de Gobierno, Sección 4, Justicia:

Orden Público-Informes.

Correspondencia-Telegramas.

Archivo de la Arquidiócesis de Pamplona:

Copiadores.

Copiadores de Comunicaciones del Señor Afanador.

Nunciatura-Santa Sede.

Pro-clero.

Archivo Secreto Vaticano, A.E.S. Colombia:

Pos. 564.

Pos. 566.

Pos. 582_584.

Fuentes Hemerográficas:

El País, periódico conservador de Bogotá.

El Porvenir, periódico conservador de Bucaramanga.

El Tiempo, periódico liberal de Bogotá.

La Unidad Católica, periódico de la diócesis de Pamplona.

Vanguardia Liberal, periódico liberal de Bucaramanga.

La Defensa, semanario conservador de Málaga.

\section{Bibliografía}

AA. Dr. Enrique Olaya Herrera, salvador de la República, 1930.

Acevedo Carmona, D. 2003. «Prensa y confrontación política en Colombia, 19301954», en VV.AA, Medios y nación: historia de los medios de comunicación en Colombia. Memorias de la VII Cátedra Anual de Historia Ernesto Restrepo Tirado. Bogotá: Aguilar.

- 1995. La mentalidad de las élites sobre la violencia en Colombia (1936-1949). Bogotá: Áncora editores.

Acuña, O. Y. 2003. «Jornadas y fraude electoral en el departamento de Boyacá. 1930-1950», en I. C. Bermúdez (comp.), Poder regional y discurso étnico: 303-333. Cali: Universidad del Valle.

- 2006: «La policía partidista en Colombia, 1930-1953». Revista Educación y Ciencia 8: 111-116.

- 2006. «Juego político y acción militar durante la República Liberal, una forma de violencia institucional», en Memorias del XIII Congreso Colombiano de Historia, (CD Rom). Bucaramanga: Universidad Industrial de Santander. 
- 2007. «Comunicación y violencia. Una mirada desde las elecciones en Boyacá, 1930-1953». Historia Caribe 12: 77-90.

Álvarez Tardío, M. Villa García, R. 2013. «El impacto de la violencia anticlerical en la primavera de 1936 y la respuesta de las autoridades». Hispania Sacra 132: 683-764.

Arbeloa, V. M. 2009. Clericalismo y anticlericalismo en España, 1767-1930. Una introducción. Madrid: Encuentro.

Arce Fustero, G. 2005. «Anticlericalismo, secularización y violencia: algunas pautas de historia comparada entre España y Colombia (1930-1948)», en A. M. Bidegaín y J. D. Demera (comps.), Globalización y Diversidad Religiosa en Colombia: 149-166. Bogotá: Universidad Nacional de Colombia.

- 2005. «Liberalismo y Catolicismo en Colombia: la lucha contra una "religiosidad africana"». Reflexión Política 13: 60-74.

- 2003. De Santos y De Diablos: Una historia comparada del conflicto político social y simbólico entre clericales y anticlericales en España y Colombia, 19301948 (Tesis de grado). Bucaramanga: Universidad Industrial de Santander, Escuela de Historia.

- 2007. «El "clero politiquero"»: la consolidación de un capital simbólico excluyente», en E. A. González Santos (ed.), Diversidad y dinámicas del cristianismo en América Latina: 397-429. Bogotá: Editorial Bonaventuriana.

Asociación de Hombres Libres de Colombia (ed.). 1962. El Concordato celebrado entre el Papa León XIII y el Dr. Rafael Núñez, presidente de Colombia. Bogotá: AHLC.

Betancourt, D. García, M. 1990. Matones y cuadrilleros. Bogotá: Tercer Mundo.

Caro Baroja, J. 2008. Historia del anticlericalismo español. Madrid: Caro Raggio Ed.

Caballero Samper, I. 2013. «La Política»: veintiún testimonios de La Violencia en las provincias Norte de Boyacá y García Rovira Santander. Bogotá: Universidad de Los Andes.

Castillo del Pino, C. 1998. «Sospecha, suspicacia, paranoidia», en C. Castillo del Pino (comp.), La Sospecha: 11-32. Madrid: Alianza Universidad.

Figueroa, H. 2007. «Clérigos y violencia en el norte de Boyacá. 1930-1946», en A. E. González (ed.), Diversidad y dinámicas del cristianismo en América Latina: 355396. Bogotá: Editorial Bonaventuriana.

Guerrero, J. 1991. Los años del olvido. Boyacá y los orígenes de la violencia. Bogotá: Tercer Mundo Editores, Instituto de Relaciones Internacionales de la Universidad Nacional de Colombia.

Guzmán, G. 1968. La Violencia en Colombia. Parte descriptiva. Cali: Progreso.

Henderson, J. 2006. Los años de Laureano Gómez, 1889-1965. Medellín: Universidad de Antioquia.

Juaristi, J. 2008. «Prólogo», en J. Caro Baroja, Historia del anticlericalismo español. Madrid: Caro Raggio Ed. 
La Parra López, E. y Suárez Cortina M. 1998. El anticlericalismo español contemporáneo. Madrid: Biblioteca Nueva.

Navarro, J. 1998. «La invención de la sospecha», en C. Castillo del Pino (comp.), La Sospecha. Madrid: Alianza Universidad.

Oquist, P. 1978. Violencia, conflicto y política en Colombia. Bogotá: Banco Popular.

Quintero Restrepo, L. D. 2008. «Los "Pájaros” del Valle del Cauca». Revista Estudios de Derecho 145: 245-257.

Salomón Chéliz, M. P. 2002. «El discurso anticlerical en la construcción de una identidad nacional española republicana (1898-1936)». Hispania Sacra 54: 485-497. 291-308.

- 2006. «Laicismo, género y religión: perspectivas historiográficas». Ayer 61:

- 2005. «Las mujeres en la cultura política republicana: religión y anticlericalismo». Historia Social 53: 103-118.

Sánchez, G. Meertens, D. 2000. Bandoleros, gamonales y campesinos, el caso de la Violencia en Colombia. Bogotá: Áncora editores.

Silva, R. 2004. «Relación de imprentas y tipografías en Colombia». Sociedad y Economía 6: 159-171.

Tirado Mejía, Á. 1995. Aspectos políticos del primer gobierno de Alfonso López Pumarejo, (1934-1938). Bogotá: Planeta.

Vázquez Piñeros, M. 2012. Iglesia y Estado en Colombia durante el gobierno de la Concentración Nacional: clero, partidos y violencia, 1929-1934 (Tesis de grado). Vitoria-Gasteiz: Universidad del País Vasco. 